\title{
Gastrodia elata Blume and its pure compounds protect BV-2 microglial-derived cell lines against $\beta$-amyloid: The involvement of GRP78 and CHOP
}

\author{
Geum-Hwa Lee' ${ }^{1}$ Hyung-Ryong Kim', Sang-Yong Han' ${ }^{1}$ Bidur Bhandary², Do-Sung Kim², Min-Gul Kim³ , Byung- \\ Ok So ${ }^{3}$, Sun-Young Kim³, Kyu-Sik Jo ${ }^{4}$, Bo-Hee Lee ${ }^{4}$, Hee-Nam Seo ${ }^{5}$, Soo-Wan Chae ${ }^{2}$, ${ }^{3}$, and Han-Jung Chae ${ }^{2}$ \\ ${ }^{1}$ Department of Dental Pharmacology and Wonkwang Dental Research Institute, School of Dentistry, Wonkwang University, Iksan, Chonbuk, South Korea \\ 2 Department of Pharmacology and Cardiovascular Research Institute, Medical School, Chonbuk National University, Jeonju, Chonbuk, South Korea \\ ${ }^{3}$ Clinical Trial Center for Functional Foods, Chonbuk National University Hospital, Jeonju, South Korea \\ ${ }^{4}$ Muju Chunma Native Local Industrial Center, Muju, Chonbuk, South Korea \\ ${ }^{5}$ Department of Pharmacy, Kangbuk Samsung Hospital, Seoul, South Korea.
}

\begin{abstract}
Objectives: Gastrodia elata (GE) Blume (Orchidaceae) has been previously known for its therapeutic benefits against neurodegenerative diseases. Microglial activation and death have been implicated in the pathogenesis of a variety of neurodegenerative diseases, including Alzheimer's disease. In this study, GE and its pure components, gastrodin and 4-hydroxybenzyl alcohol (4HBA), were applied to $\beta$-amyloidinduced BV2 mouse microglial cells.

Materials and Methods Cell viability was assessed by the MTT assay and Western blotting was also performed.

Results: $\beta$-amyloid-induced cell death was shown to be induced time- and dose-dependently. To examine the cell death mechanism, we confirmed the involvement of ER stress signaling. C/EBP homologous protein (CHOP), a pro-apoptotic ER stress protein, was expressed at high levels but glucose-regulated protein 78 (GRP78), an anti-apoptotic ER stress protein with chaperone activity, was only slightly affected by treatment with $\beta$-amyloid. However, pretreatment with GE and its components inhibited the expression of CHOP but increased that of GRP78 in $\beta$-amyloid-treated cells. This study also showed that a single treatment with GE extracts, gastrodin, or $4 \mathrm{HBA}$ induced the expression of GRP78, a marker for enhanced protein folding machinery, suggesting a protective mechanism for GE against $\beta$-amyloid. Conclusions: This study reveals the protective effects of GE against $\beta$-amyloid-induced cell death, possibly through the enhancement of protein folding machinery of a representative protein, GRP78, and the regulation of CHOP in BV2 mouse microglial cells.
\end{abstract}

Key words: Gastrodia elata, 4HBA, GRP78, CHOP, $\beta$-amyloid.

\section{INTRODUCTION}

Alzheimer's disease, the most common form of dementia, is a chronic neurodegenerative disease that causes the progressive impairment of memory and other cognitive functions. Neuritic plaques, neurofibrillary tangles and neuronal loss represent the primary pathological characteristics in the brains of Alzheimer's patients. Amyloid $\beta$-protein ( $\beta$-amyloid), the central component of senile plaques, is produced from sequential proteolytic cleavages of type I transmembrane $\beta$-amyloid precursor protein by $\beta$ - and $\gamma$-secretases [Glenner and Wong, 1984, Hardy and Selkoe, 2002]. The integrity of adult mouse brain neurogenesis in Alzheimer's diseaseassociated pathological models has also been examined [Siman et al., 2000]. The mouse brains studied exhibited amyloid deposition and microgliosis. It has also been reported that $\beta$-amyloid accelerates neurodegeneration by activating microglia and that the activated microglia exert cytotoxic effects on neurons [Ryu et al., 2009, Folden et al., 2005]. In addition to neuronal cells, microglial CNS-resident professional sensor cells also respond to many pathological events. Localized activation of microglia has been implicated in the pathogenesis of a variety of neurodegenerative diseases, including Alzheimer's disease. Aggregated $\beta$-amyloid has been shown to interfere with several cellular processes and can result in endoplasmic reticulum (ER) stress. As neurons are highly susceptible to the toxic effects of the aggregated $\beta$-amyloid of Alzheimer's disease, ER-stress-mediated cell death might have an important role in the pathogenesis of this disease [Wiley et al., 2010, Chafekar et al., 2008].

Under normal conditions a chaperone protein, glucoseregulated protein 78 (GRP78), sequesters three key signal transducers on the ER membrane by forming an inactive complex that includes a double-stranded RNA-activated protein kinase-like ER kinase (PERK), activating transcription factor 6 (ATF-6), and inositol-requiring transmembrane kinase and endonuclease, IRE-1 [Bertolotti et al., 2000, Xu et al., 2005]. Dissociation from GRP78 is required for the activation of the three key signal transducers. The activation results in a decrease in translation, increased protein degradation and increased levels of ER chaperones. When there is prolonged ER stress the cells can no longer maintain homeostasis, and thus the cell death signaling pathway is triggered [Kim et al., 2008, $\mathrm{Gu}$ et al., 2010]. In contrast, an adaptive ER stress response known as the unfolded protein response (UPR), including XBP-1 and GRP78, has been suggested to have a protective role against ER stress through enhancement of the protein-folding capacity, a protective mechanism against ER stress-associated neuronal degenerative diseases including Alzheimer's disease [Casas-Tinto et al., 2011, Kogel et al., 2003].

There have been continuous efforts to develop drugs or nutraceuticals to treat or prevent Alzheimer's disease. Numerous candidate treatment agents have been examined, including various kinds of herbal and natural products. 
Among these natural compounds, Gastrodia elata (GE) has demonstrated its potential, considering that the material was traditionally and frequently used for cerebral ischemia or symptoms similar to those of Alzheimer's disease. In addition, gastrodin, the primary component of the functional extracts of GE, can reduce the seizure score in seizure-prone gerbils and facilitate learning and memory [Hsieh et al., 1997]. In addition, some studies found that gastrodin had protective effects in rat cortical neurons and astrocytes against damage induced by in vitro simulated cerebral ischemia, and gastrodin has been associated with a decreased mortality rate resulting from ischemia in mice [Zeng et al., 2007]. 4-Hydroxybenzyl alcohol (4HBA), an aglycone of gastrodin and an active ingredient of GE, attenuates learning deficits in an inhibitory avoidance task, suggesting that $4 \mathrm{HBA}$ may act by suppressing dopaminergic and serotonergic activities, thereby improving learning abilities [Wu et al., 1996]. Although microglial cells are also important for the pathological conditions of neurodegenerative diseases, fewer studies have been conducted with microglial cells than with neuronal cells. Since the ways in which GE and its pure components facilitate the learning and memory processes and protect against neuron damage have not yet been clarified, GE and its components were applied to mouse microglial cells, BV2 cells.

In this study, the functional roles and mechanisms of GE and its pure components in the protection against $\beta$-amyloidinduced microglial cell death were investigated.

\section{MATERIALS AND METHODS}

\section{Materials}

Dried Gastrodia elata was acquired from the MooJoo Hangto Research Group (MooJoo, Korea). 26.52 g of G. elata powder was prepared from $1800 \mathrm{~g}$ of dried G. elata; three replicates were cut into small pieces and extracted with $1500 \mathrm{ml}$ of $100 \%$ methanol at $60{ }^{\circ} \mathrm{C}$ for $3 \mathrm{~h}$. The extract was filtered and evaporated in a rotary vacuum evaporator at $50{ }^{\circ} \mathrm{C}$ before being freeze-dried. Lyophilized, HPLC-purified $\beta$-amyloid (1-42 peptides) was purchased from American Peptide (Sunnyvale, CA) and $\beta$-amyloid reconstituted in sterile water at a concentration of $400 \mu \mathrm{m}$ and incubated at $37^{\circ} \mathrm{C}$ for $3 \mathrm{~d}$ or $24 \mathrm{hr}$ to form aggregated $\beta$-amyloid, or maintained at $4{ }^{\circ} \mathrm{C}$ in soluble or nonaggregated form. Oligomeric and fibrillar $\beta$-amyloid were prepared using the method of Karie et al [2002]. The antibodies against actin, GRP78, PERK, IRE-1, spliced XBP-1 and CHOP were acquired from Santa Cruz Biotechnology (SantaCruz, CA). The antibodies against eIF$2 \alpha$ and phospho-eIF-2 $\alpha$ were purchased from Cell Signaling Technologies (Beverly, Mass). All other chemicals were of at least analytical grade and were purchased from Sigma Chemical Company (St. Louis, MO).

\section{Cell culture}

The BV2 mouse microglial cell line [Byun et al., 2012] was cultured in DMEM supplemented with $10 \%$ fetal bovine serum and a $1 \%$ penicillin-streptomycin mixture (Invitrogen, Carlsbad, CA) at $37^{\circ} \mathrm{C}$ in a humidified incubator $\left(5 \% \mathrm{CO}_{2}\right.$ and 95\% air). Cells were plated one day before treatment at $80 \%$ density according to each experimental scale.

\section{Determination of cell viability}

Cell viability was measured and calculated using the MTT reduction assay, as described previously [Yu et al., 2008]. After the incubation of BV2 cells $\left(4 \times 10^{4}\right.$ cells $/ 300 \mu \mathrm{L}$ in 24 -well plates) with oligomeric and fibrillar $\beta$-amyloid (1-42 amino acid residues) for various time periodss in the presence or absence of GE or one of its pure components, gastrodin or 4HBA, MTT solution (final concentration $1 \mathrm{mg} / \mathrm{ml}$ ) was added. The dark blue formazan crystals, which formed in viable cells with normal mitochondrial function, were dissolved with dimethyl sulfoxide (DMSO), and the absorbance at $570 \mathrm{~nm}$ was measured with a microplate reader (EMax, Molecular Device, Sunnyvale, CA, USA). Cell viability was expressed as percentage (\%) MTT reduction, assuming that the optical density of formazan formed in the vehicle-treated control cells was $100 \%$.

Caspase-3 activity assay

Cytosolic cell extracts were prepared by lysing the cells in a buffer containing 1\% Nonidet P-40, $200 \mathrm{mM} \mathrm{NaCl}, 20 \mathrm{mM}$ Tris/ $\mathrm{HCl}, \mathrm{pH} 7.4,10 \mathrm{Ag} / \mathrm{ml}$ leupeptin, aprotinin (0.27 trypsin inhibitor $/ \mathrm{U} / \mathrm{ml}$ ) and 100 AM PMSF. The caspase protease activity was determined by incubating the cell lysates (25 $\mathrm{Ag}$ of total protein) with $50 \mathrm{AM}$ of a fluorogenic substrate, AC-DEVD-AMC (caspase-3) in a cell-free buffer system (10 mM HEPES, pH 7.4, $220 \mathrm{mM}$ mannitol, $68 \mathrm{mM}$ sucrose, $2 \mathrm{mM}$ $\mathrm{NaCl}, 2.5 \mathrm{mM}$ KH2PO4, $0.5 \mathrm{mM}$ EGTA, $2 \mathrm{mM} \mathrm{MgCl2}, 5 \mathrm{mM}$ pyruvate, $0.1 \mathrm{mM}$ PMSF, and $1 \mathrm{mM}$ dithiothreitol). The release of fluorescent 7-amino-4-methylcoumarin was measured at 2-min intervals for $1 \mathrm{~h}$ using a spectrofluorometer at an excitation wavelength of $365 \mathrm{~nm}$ and an emission wavelength of $460 \mathrm{~nm}$.

\section{Hoechst staining}

Cell nuclei were stained with chromatin dye (Hoechst 33258). Briefly, cells were fixed with $3.7 \%$ paraformaldehyde for $10 \mathrm{~min}$ at room temperature, washed twice with PBS and incubated with $10 \mu \mathrm{M}$ Hoechst 33258 in PBS at room temperature for $30 \mathrm{~min}$. After three washes, cells were observed under a fluorescence microscope (MPS 60, Leica).

\section{Western blotting}

After drug treatment for the indicated times, treated cells were harvested by washing twice with ice-cold PBS and the cell pellet was obtained by centrifuging at 3,000 rpm for 5 min. After removing the supernatant, cells were lysed on ice through the addition of RIPA lysis buffer $(50 \mathrm{mM}$ Tris- $\mathrm{HCl} \mathrm{pH}$ $7.4,150 \mathrm{mM} \mathrm{NaCl}, 0.25 \%$ sodium deoxycholate, $1 \% \mathrm{NP} 40,1$ $\mathrm{mM}$ EDTA, $0.1 \%$ SDS), protease inhibitor cocktail set III, and phosphatase inhibitor cocktail set II (EMD Biosciences, La Jolla, CA, USA). Cell lysates were transferred to microtubes and incubated for $30 \mathrm{~min}$ on ice, followed by centrifugation at $12,000 \mathrm{rpm}$ for $10 \mathrm{~min}$ at $4{ }^{\circ} \mathrm{C}$. Supernatants were collected and used as protein extracts. Protein extracts were added to sample buffer, boiled in a water bath for $5 \mathrm{~min}$, and stored at $-20{ }^{\circ} \mathrm{C}$ until use. Samples of $10 \mu \mathrm{g}$ of protein extract were analyzed on a polyacrylamide gel and transferred onto a nitrocellulose membrane, which was blocked for $30 \mathrm{~min}$ at 
room temperature with TBS containing 0.05\% Tween-20. Blots were probed overnight at $4{ }^{\circ} \mathrm{C}$ with appropriate antibodies, washed, and probed again with species-specific secondary antibodies coupled to horseradish peroxidase (Santa Cruz, CA, USA). Chemiluminescent reagents (GE Healthcare, Piscataway, NJ, USA) were added for blot detection, and immunoreactive bands were visualized using an LAS-3000 Imager (Fuji Film, Japan).

Statistical analysis

Results are presented as mean \pm SEM of $n$ experiments; one-way ANOVA was used for comparison and post-hoc tests to compare different groups. OriginPro7.5 software [Northampton, MA, USA] was used for the statistical calculations.

\section{RESULTS}

\section{$\beta$-Amyloid induces cell death as an ER stress response in BV2 cells}

MTT reduction assays were performed to assess $ß$-amyloidinduced toxicity. Oxidoreductase, a mitochondrial enzyme, converts MTT to a crystalline blue formazan in viable cells. The $\beta$-amyloid-induced toxicity was assessed in BV2 cells after incubation with different concentrations of $\beta$-amyloid $(5,10,15$, or $20 \mu \mathrm{M}$ ) for 48 hours. A dose-response curve was created for percentage cell viability against the concentration of $\beta$-amyloid (Fig. 1A). Caspase-3 activity was also examined in the treated cells. Caspase- 3 activity was also increased by treatment with $\beta$-amyloid (right). Similarly, we assessed the timedependent response of $\beta$-amyloid-induced cytotoxicity. For this experiment, we incubated BV2 cells with $\beta$-amyloid (10 and 20 $\mu \mathrm{M})$ and assessed cell viability at different time intervals (6, $12,24,36$, and 48 hours). Cell viability and caspase- 3 activity clearly increased in a time-dependent manner (Fig. 1B). In addition, nuclei staining clearly showed apoptosis in 10 or 20 $\mu \mathrm{M} \beta$-amyloid-treated cells (Fig. 1B, right).

To determine the activation status of major ER stress sensors including GRP 78, CHOP, IRE- $1 \alpha$, spliced XBP-1, PERK and p-eIF2 $\alpha$, we performed Western blot analysis with specific antibodies in neuronal cells treated with increasing concentrations of $\beta$-amyloid $(5,10,15$, and $20 \mu \mathrm{M})$ for 24 hours. Interestingly, the levels of CHOP, IRE- $1 \alpha$, spliced XBP-1, PERK, and p-eIF2 $\alpha$ were markedly increased at all concentrations of $\beta$-amyloid, although the expression of GRP78 was only slightly affected, showing a slightly increased pattern in the presence of low concentrations of $\beta$-amyloid (Fig. 1C). Similarly, we observed increased ER stress protein expression when cells were treated for various durations of time $(0,3,6,9,12,18$, or 24 hours) with $15 \mu \mathrm{M} \beta$-amyloid (Fig. 1D). The expression of GRP78, a well-known chaperone protein, was not affected by the presence of $\beta$-amyloid. The quantitative analysis of each protein is shown in the lower panel.

GE, gastrodin, and $4 H B A$ regulate $\beta$-amyloid-induced cell death and have a regulatory effect on $E R$ stress proteins in $B V 2$ cells

The MTT assay relies primarily on the mitochondrial metabolic capacity of viable cells and reflects the intracellular redox state. After the incubation of BV2 cells pretreated with $\beta$-amyloid alone or together with GE, gastrodin, or $4 \mathrm{HBA}$, the cells were treated with MTT solution. The experimental results showed that the cytotoxicity induced by $\beta$-amyloid was inhibited in the presence of GE, gastrodin, or 4HBA (Fig. 2A, left). The time-response cell viability percentage was also measured in BV2 cells with the same pretreatments (i.e., $\beta$-amyloid alone or together with GE, gastrodin, or 4HBA for 6, 12, 24, 36, and 48 hours). We observed the inhibition of $\beta$-amyloid-induced toxicity in cells pretreated with GE, gastrodin, or $4 \mathrm{HBA}$ up to 48 hours (Fig. 2A, right). Fig. 2B shows that caspase- 3 activity was also correlated with the MTT assay. With the treatment of GE, gastrodin or $4 \mathrm{HBA}$, the caspase-3 activity was significantly inhibited in $\beta$-amyloid-treated cells. Consistently, Hoechst staining data confirmed the protective effect of GE and its components against $\beta$-amyloid-induced apoptosis (Fig. 2C). To test whether GE-, gastrodin-, or 4HBA-induced protection is related to ER stress, we analyzed the levels of ER stress proteins; GRP78, a chaperone protein with protective roles, and $\mathrm{CHOP}$, an executive transcription factor for pro-apoptotic genes, using Western blot analysis of the lysates of cells treated with GE, gastrodin, or 4HBA. The results showed that CHOP expression induced by $\beta$-amyloid was inhibited in the presence of GE, gastrodin, or 4HBA (Fig. 2D). The GRP78 signal, which was not affected by $\beta$-amyloid treatment, was somewhat increased by GE and its components. Figure 2E also shows the concentration-dependent regulation of GE and its components on GRP78 and CHOP expressions in the BV cells. The quantitative data of the protein expressions are shown in the lower panel.

GE, gastrodin, or $4 H B A$ alone induce the expression of the chaperone protein, GRP78

Since GRP78 is a chaperone protein which enhances protein folding and rehabilitation of the unfolded protein, we tested the effects of GE, gastrodin, and 4HBA on the expression of GRP78 in the absence of $\beta$-amyloid. The expression of GRP78 was significantly increased by treatment with GE, gastrodin, or 4HBA (Fig. 3A). The quantitative results of GRP78 expression are shown in the lower panel of Fig. 3A. At $10 \mu \mathrm{g} /$ $\mathrm{ml}$ of GE, gastrodin, or $4 \mathrm{HBA}$, a time-dependent increase in the expression of GRP78 in BV2 cells was observed (Fig. 3B). However, there was no expression of $\mathrm{CHOP}$, another ER stress protein, in the presence of GE, gastrodin, or 4HBA (data not shown). This study suggests that a chaperone protein expression and its linked chaperone function may be related to the ER stress response and its related cell death regulation in $\beta$-amyloid-treated BV cells.

\section{DISCUSSION}

In this study, Gastrodia elata (GE) protected microglial cells against $\beta$-amyloid-induced cell death. Two major components of GE, gastrodin and $4 \mathrm{HBA}$, also regulated $\beta$-amyloid-induced cell death. $\beta$-amyloid-induced ER stress response was also regulated by GE and its components, gastrodin and 4HBA, through the expression of a chaperone protein, GRP78. GE protected cells against $\beta$-amyloid-induced cell death in an in vitro model of Alzheimer's disease. GE shows promise as a potential agent for use against Alzheimer's disease. The natural compound has been traditionally used for cerebral ischemia or symptoms similar to those of Alzheimer's disease [Yu et al., 2005, Wu et al., 2010, Park et al., 2009]. Furthermore, 

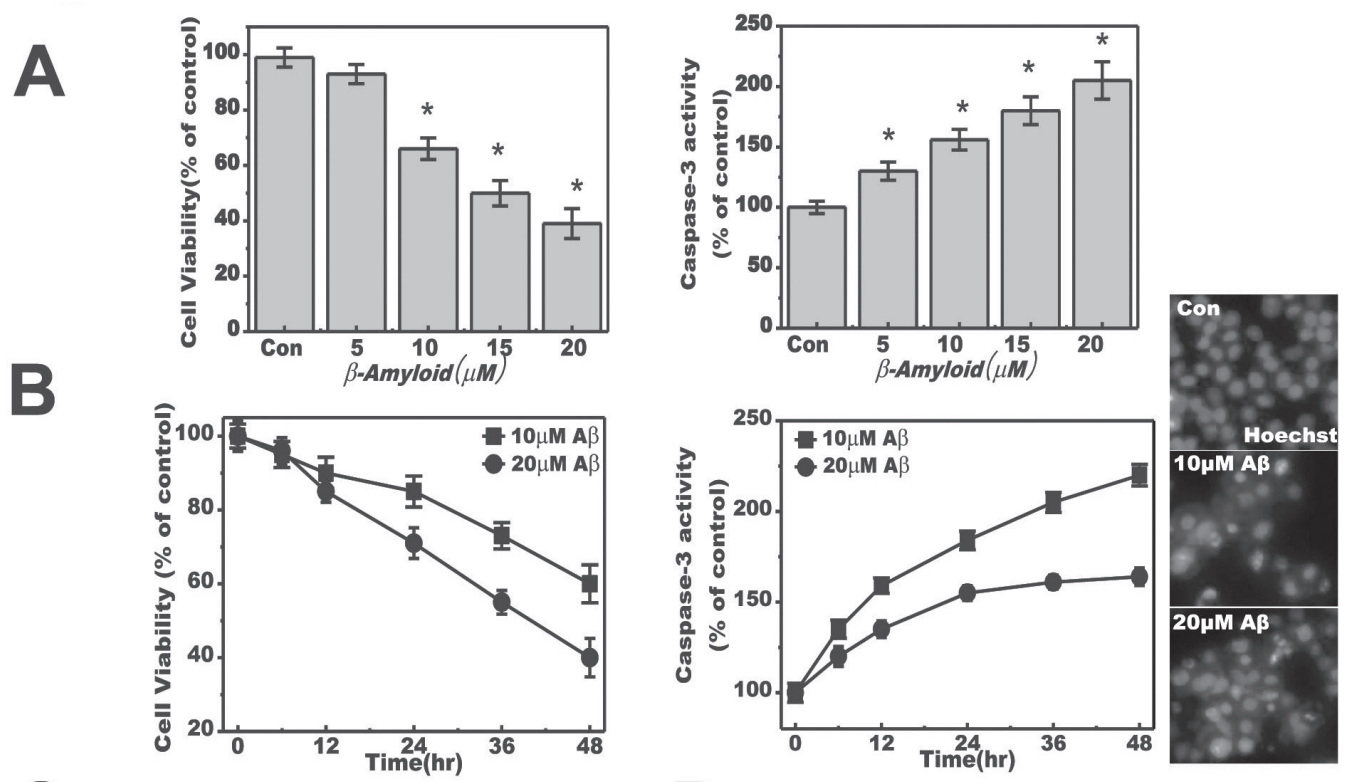

C
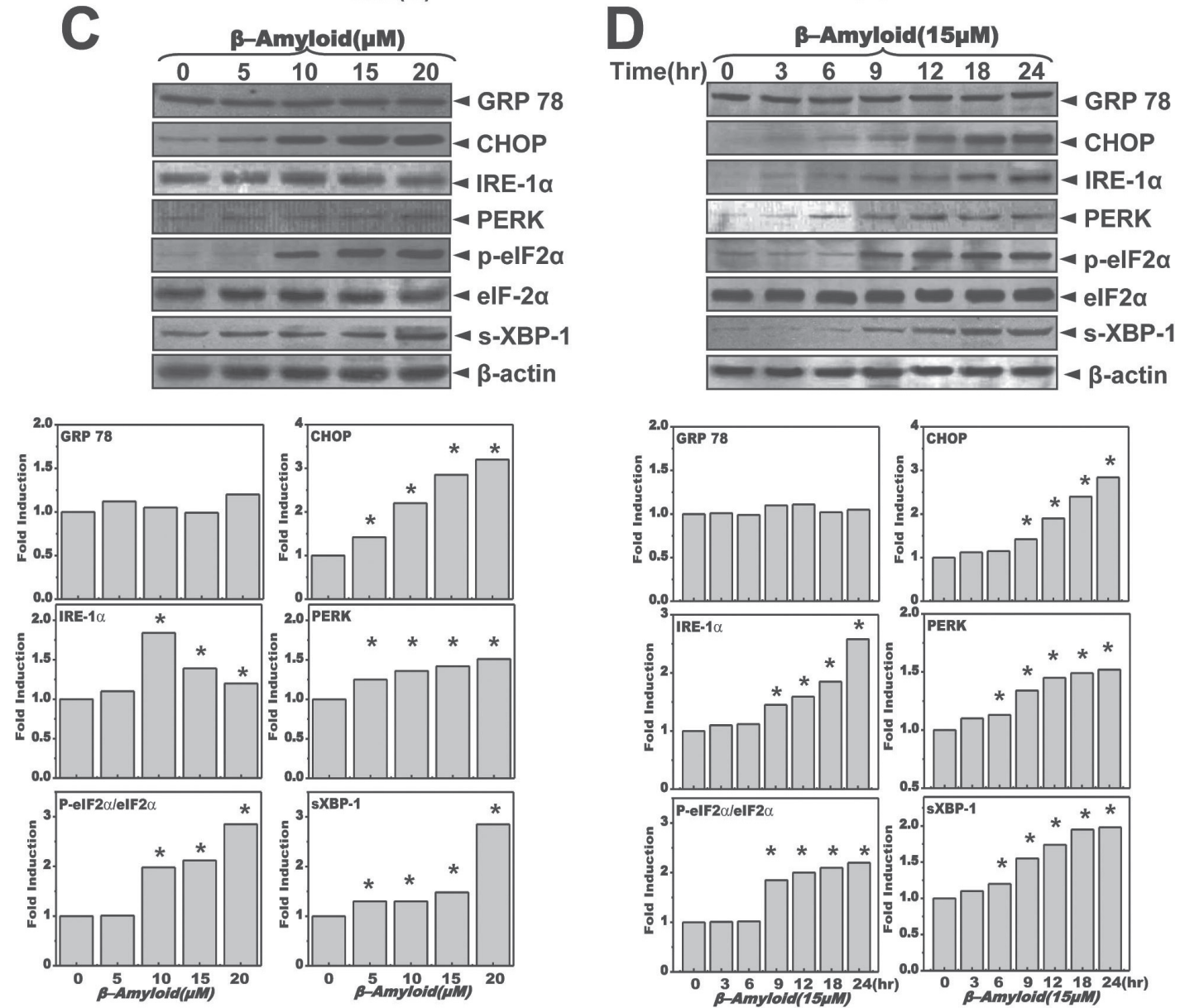

Figure 1: $\beta$-Amyloid induces cell death and causes ER stress response in BV2 cells.

BV2 cells were treated with the indicated concentrations of $\beta$-amyloid for a 48-hour period (A). Separately, BV2 cells were treated with 10 or $20 \mu \mathrm{M} \beta$-amyloid for the indicated time periods (B) and MTT and caspase-3 activity assays were conducted. BV2 cells were treated with 10 or $20 \mu \mathrm{M} \beta$-amyloid for 48 hours and Hoechst staining was performed as described in Materials and Methods (right). BV2 cells were treated with the indicated concentrations of $\beta$-amyloid for 48 hours (C). Separately, BV2 cells were treated with $15 \mu M \quad \beta$-amyloid for the indicated time periods (D) and immunoblotting was performed with antibodies to GRP78, CHOP, IRE- $1 \alpha$, spliced XBP-1, PERK, p-elF2 $\alpha$, elF $2 \alpha$, or $\beta$-actin. Representative data is shown from three independent experiments. Quantification of the protein density is shown in the lower panel. ${ }^{*} p<0.05$, significantly different from the control. 



B
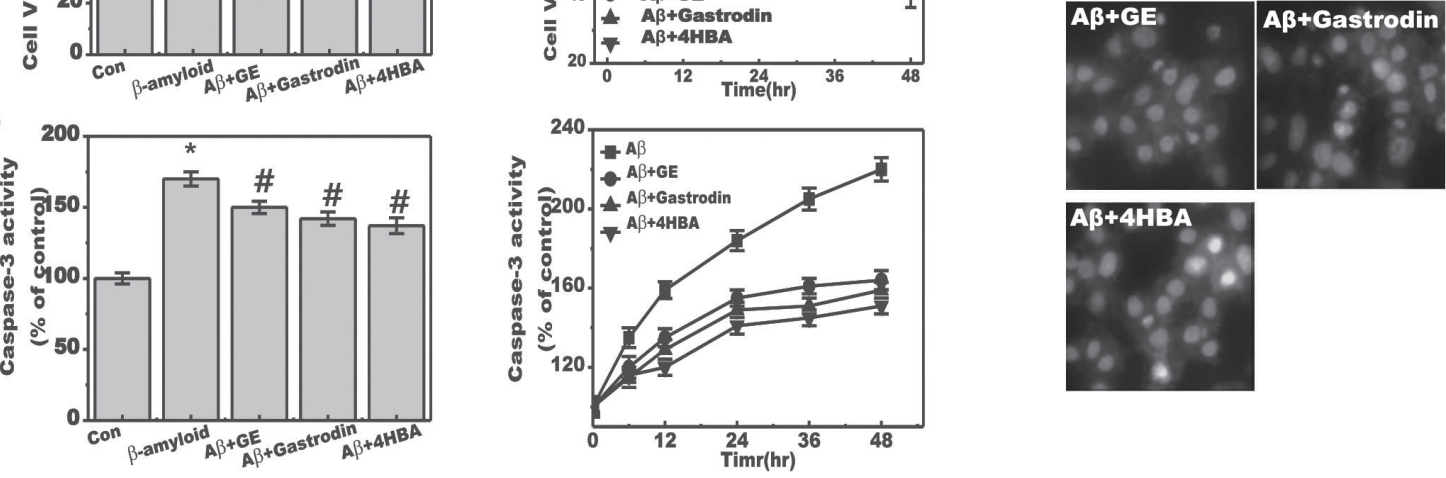

D


Figure 2: $G E$, gastrodin, and $4 \mathrm{HBA}$ regulate $\beta$-amyloid-induced cell death and show a regulatory effect on ER stress proteins in BV2 cells. BV2 cells were treated with $20 \mu \mathrm{M} \beta$-amyloid with or without $10 \mu \mathrm{g} / \mathrm{ml} \mathrm{GE}$, gastrodin, or $4 \mathrm{HBA}$ for 48 hours (A, B, left). Separately, BV2 cells were treated with $10 \mu \mathrm{g} / \mathrm{ml} \mathrm{GE}$, gastrodin, or 4HBA with $20 \mu \mathrm{M} \beta$-amyloid for the indicated times (A, B, right) and MTT and caspase-3 activity assays and Hoechst staining (C) were performed. BV2 cells were treated with $10 \mu \mathrm{g} / \mathrm{ml} \mathrm{GE}$, gastrodin, or 4HBA with 20 $\mu \mathrm{M} \beta$-amyloid for 24 hours and immunoblotting was performed with antibodies to GRP78, CHOP, IRE-1 $\alpha$, spliced XBP-1, PERK, p-elF-2 $\alpha$, elF- $2 \alpha$ or $\beta$-actin (C). BV2 cells were treated with the indicated concentrations of GE, gastrodin, or 4HBA with $20 \mu \mathrm{M} \beta$-amyloid for 24 hours, and immunoblotting was performed with antibodies to GRP78, CHOP, IRE-1 $\alpha$, spliced XBP-1, PERK, P-elF-2 $\alpha$, elF- $2 \alpha$ or $\beta$-actin (D). Representative data is shown from three independent experiments. Quantification of the protein density is shown in the lower panel. ${ }^{*} p<$ 0.05 , significantly different from the control; ${ }^{*} p<0.05$, significantly different from $\beta$-amyloid-treated cells. 

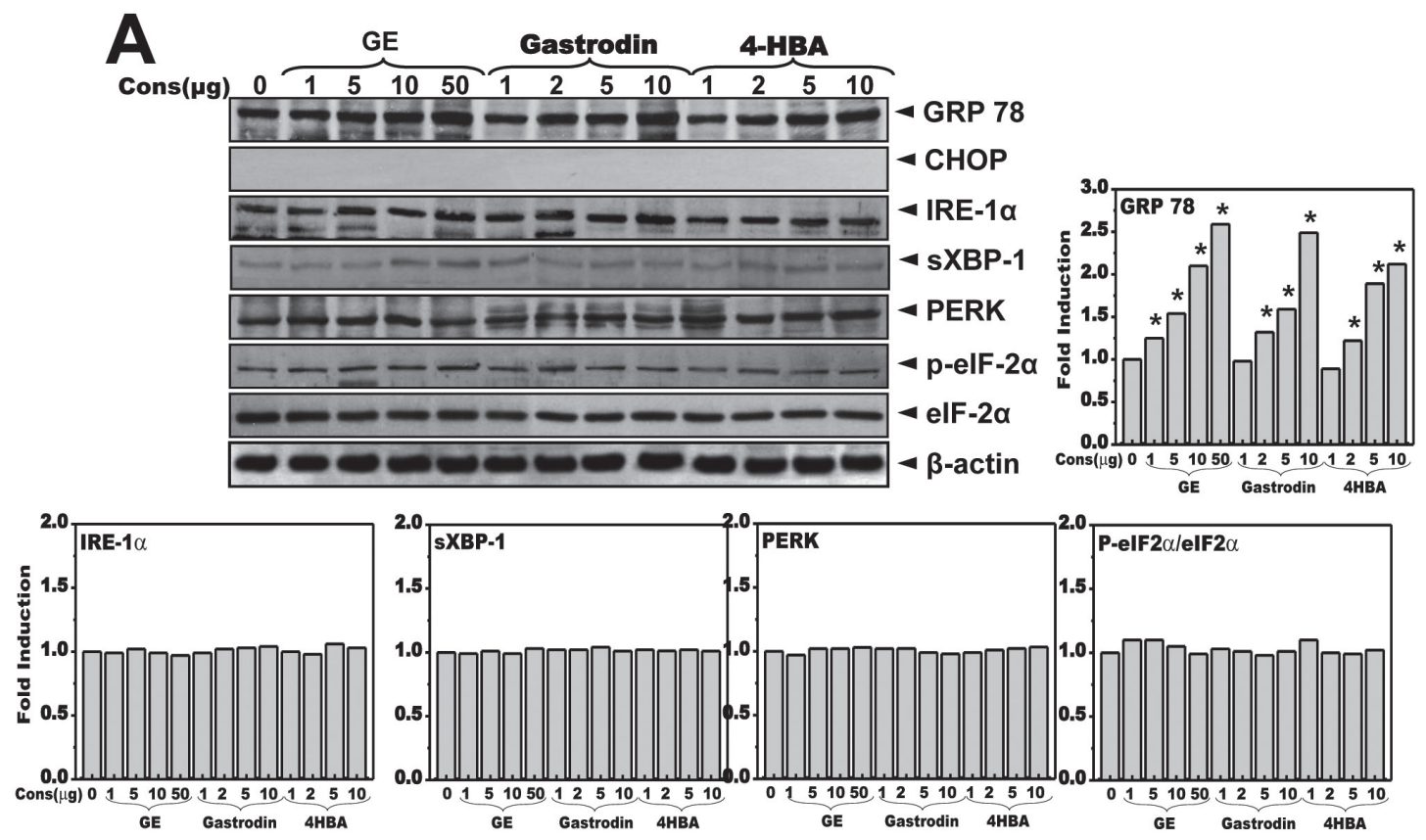

B
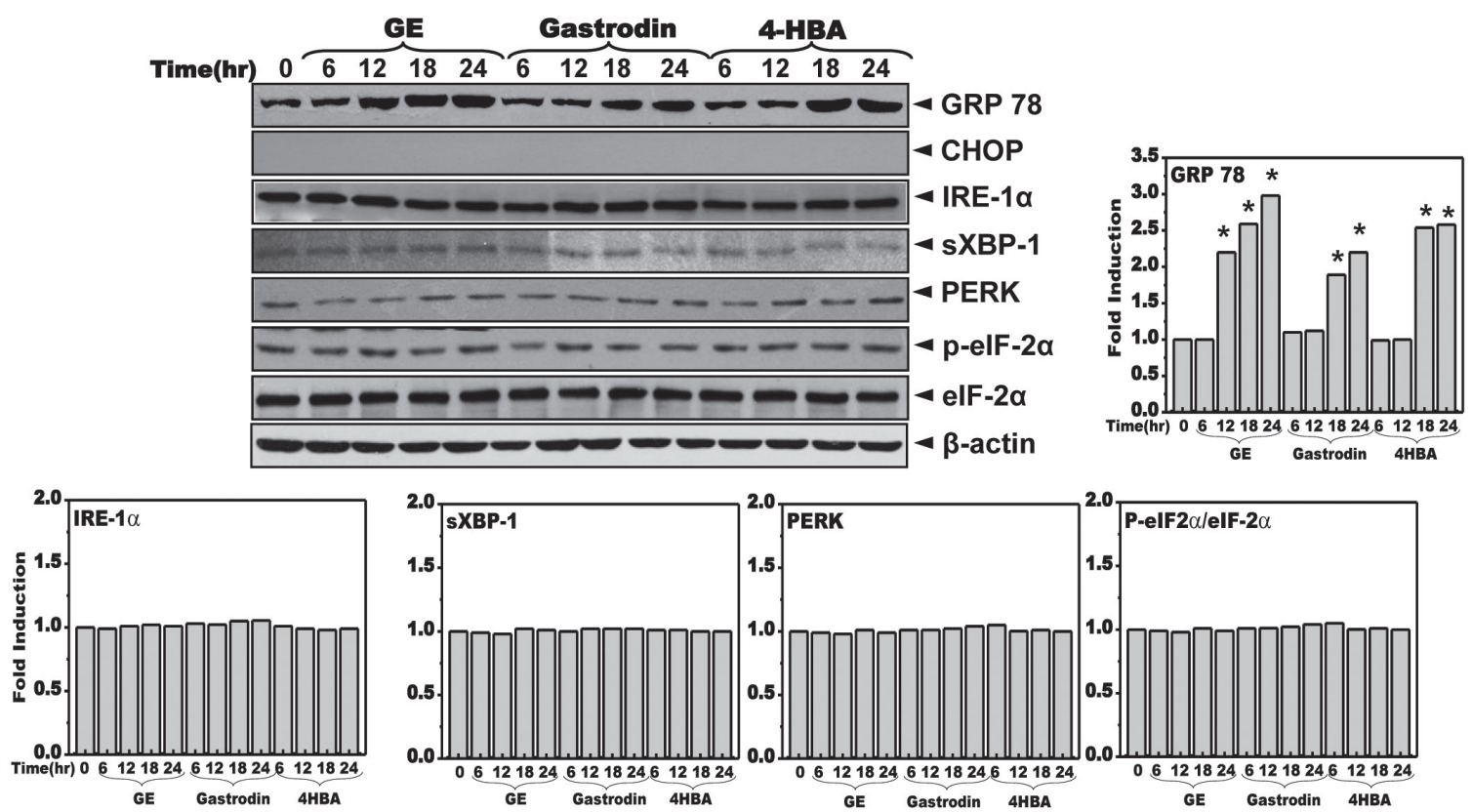

Figure 3: GE, gastrodin, and 4HBA induce the expression of the chaperone protein, GRP78. BV2 cells were treated with the indicated concentrations of GE, gastrodin or $4 \mathrm{HBA}$ for 24 hours (A). Separately, BV2 cells were treated with $10 \mu \mathrm{g} / \mathrm{ml}$ of GE, gastrodin, or $4 \mathrm{HBA}$ during the indicated time periods (B) and immunoblotting was performed with anti-GRP78, CHOP, IRE- $1 \alpha$, spliced XBP-1, PERK, p-elF-2 $\alpha$, elF- $2 \alpha$ or $\beta$-actin antibody. Representative data is shown from three independent experiments. Quantification analysis was performed using densitometry (lower). ${ }^{*} p<0.05$, significantly different from the control. 
gastrodin and 4HBA showed effects similar to those of GE. The role of gastrodin in facilitating learning and memory was previously investigated [Wu et al., 1996, Hsieh et al., 1997]. It has also been reported that gastrodin has protective effects against cerebral ischemia-induced neuronal cell death [Yu et al., 2005, Xu et al., 2007]. Furthermore, a gastrodinmediated decrease in mouse mortality rate was also correlated with the in vitro results [Zeng et al., 2007]. In addition to GE, several potential drug or natural product candidates to treat or prevent Alzheimer's disease have been discovered, including curcuminoids from Curcuma longa (turmeric) [Ahmed and Gilani, 2009], shogaols from Zingiber officinale (ginger) [Ghayur et al., 2008], huperzine from herbal moss Huperzia serrata (toothed clubmoss) [Zhang et al., 2008], and galanthamine from Ungernia sp. (daffodil bulbs) [Keller et al., 2011]. In another study of the protective effects of herbs and natural compounds against neurotoxicity, Uncariae Ramulus et Uncus, Gastrodia elata, Evodia officinalis and Panax ginseng were the most successful [Kim et al., 2006]. These findings suggest that these plants are also potential candidates with neuroprotective effects that could be useful in the treatment of neurodegenerative diseases such as Alzheimer's disease. However, these plant extracts represent only a small fraction of the herbs used worldwide. Thus, it is of interest to identify additional herbs that could be used as sources for new potential drug candidates to treat Alzheimer's disease. Additionally, the known candidates for the treatment of Alzheimer's disease require further study, especially with respect to the mechanisms responsible for their potential effects against Alzheimer's disease models in vitro and in vivo.

This study suggests a mechanism that involves the regulation of $\beta$-amyloid-induced cell death through GRP78 expression. Stress conditions such as glucose starvation, energy deficiency, chemical toxicity, acidosis and hypoxia, oxidative stress, ER $\mathrm{Ca}^{2+}$ depletion and inhibitors of glycosylation also cause increased cell damage and the induction of the glucoseregulated protein family members [Casas-Tinto et al., 2011, Kogel et al., 2003]. GRP78 was identified as a prototypic ER stress marker and master regulator of unfolded protein response (UPR). The accumulation of misfolded proteins in the ER due to environmental and/or metabolic stress conditions triggers GRP78 liberation from transmembrane ER signaling proteins to initiate GRP78 mRNA re-synthesis. Under normal or protective conditions, the GRP78 protein prevents the release of ATF6 from the ER membrane and the expression of CHOP, a transcription factor of pro-apoptotic genes, which acts as its own negative regulator [Casas-Tinto et al., 2011, Kim et al., 2008]. Throughout this study, the expression of GRP78 is suggested as a protective mechanism. Similarly, several studies have revealed the role of GRP78 as a protective chaperone protein against pathological conditions. It was reported that GRP78 has an essential role against neuronal apoptosis [Wang et al., 2010, Yuet al., 1999]. In other cell types such as cardiomyocytes and renal epithelial cells, GRP78 expression has been suggested as a main protective mechanism against programmed cell death [Xiao-Hong et al., 2006, Liu et al., 1997].

Our finding regarding the involvement of GRP78 and the ER stress response in $\beta$-amyloid-induced cell death regulation with GE is novel, given that previous reports showing the beneficial effects of GE/pure components only linked the benefits to the antioxidant properties of the substances or to a mitochondrial cell death mechanism [An et al., 2010, Yu et al., 2005]. In this study, the observed increase in GRP78 levels due to GE application may reflect an adaptation by the cell for increased protein synthesis in order to avoid ER overload. Upon $\beta$-amyloid treatment we observed an increase in cell death, in which the expression of GRP78 changed slightly at a relatively low concentration of $\beta$-amyloid, $5 \mu \mathrm{M}$, but not at other concentrations $(10,15$, or $20 \mu \mathrm{M})$. However, the expression of a pro-apoptotic protein, CHOP, was strongly increased in a $\beta$-amyloid concentration-dependent manner (Fig. 1C). The elevated expression of CHOP could be interpreted as $\beta$-amyloid-associated cell death, just as the GEmediated reduction in $\mathrm{CHOP}$ expression might be explained as one of the protective mechanisms of GE against $\beta$-amyloid stimuli. In Fig. 2D, GE and its components inhibited the expression of CHOP, the pro-apoptotic ER stress protein, while increasing that of GRP78, the anti-apoptotic chaperone protein. Consistent with this, concentration-dependent regulation of GRP78 and CHOP expression in BV cells was shown in Fig. 2E. Although the GE-induced expression of GRP78 provides a protective mechanism against $\beta$-amyloid, prolonged treatment with GE will not overcome the deleterious effects of chronic $\beta$-amyloid exposure, generally longer than four days, nor will it counteract the effects of an excessively high concentration of $\beta$-amyloid. These findings indicate the possibility of multiple mechanisms that facilitate cognition and memory without providing a cell-protective function. However, our results highlight a novel mechanism, whereby GE may inhibit the progression to Alzheimer's disease by allowing for a temporary adaptation to cell stress, a cellular protection phenotype that lasted for at least a few days in an in vitro study model.

In conclusion, GE and its pure components, gastrodin and $4 \mathrm{HBA}$, protect against $\beta$-amyloid-induced cell death. The protective mechanism involved is suggested to be the induction of the chaperone ER stress protein, GRP78. However, further studies are needed to clarify the in vivo neuroprotective effects of GE, gastrodin, and 4HBA.

\section{ACKNOWLEDGEMENTS}

This study was supported by funding from the MooJoo Hyangto Research Group (2010).

\section{REFERENCES}

AHMED T, GILANI AH (2009) Inhibitory effect of curcuminoids on acetylcholinesterase activity, attenuation of scopolamine-induced amnesia may explain medicinal use of turmeric in Alzheimer's disease. Pharmacol Biochem Behav 91(4): 554-559.

AN H, KIM IS, KOPPULA S, KIM BW, PARK PJ, LIM BO, CHOI WS, LEE KH, CHOI DK (2010) Protective effects of Gastrodia elata Blume on $\mathrm{MPP}+$-induced cytotoxicity in human dopaminergic SH-SY5Y cells. J Ethnopharmacol 130(2): 290-298.

BERTOLOTTI A, ZHANG Y, HENDERSHOT LM, HARDING HP, RON $\mathrm{D}$ (2000) Dynamic interaction of BiP , ER stress transducers in the unfolded-protein response Nat Cell Biol 2(6): 326-32.

BYUN CJ, SEO J, JO SA, PARK YJ, KLUG M, REHLI M, PARK MH, JO I (2012) DNA methylation of the $5^{\prime}$-untranslated region at +298 and +351 represses BACE1 expression in mouse BV-2 microglial cells. Biochem Biophys Res Commun 417(1):387-92.

CASAS-TUNTO S, HANG Y, SÁNCHEZ-GARCÍA J, GÓMEZ-VELÁZQUEZ M, RINCON-LIMAS DE, FERNEZ-FUNEZ P (2011) The ER stress factor XBP1s prevents amyloid-\{beta\} neurotoxicity. Hum Mol Genet 20(11): 2144-2160.

CHAFEKAR SM, ZWART R, VEERHUIS RV, ERSTICHELE H, BAAS F, SCHEPER W (2008) Increased Abeta1-42 production sensitizes 
neuroblastoma cells for ER stress toxicity. Curr Alzheimr Res 5(5): 469474.

FOLDEN AM, LI S, COMBS CK (2005) Beta-amyloid-stimulated microglia induce neuron death via synergistic stimulation of tumor necrosis factor alpha, NMDA receptors J Neurosci 25(10): 2566-75.

GLENNER GG, WONG CW (1984) Alzheimer's disease: initial report of the purification, characterization of a novel cerebrovascular amyloid protein. Biochem Biophys Res Commun 120: 885-890.

GHAYUR MN, GILANI AH, AHMED T, KHALID A, NAWAZ SA, AGBEDAHUNSI JM, CHOUDHARY MI, HOUGHTON PJ (2008 Muscarinic $\mathrm{Ca}(++)$ antagonist, specific butyrylcholinesterase inhibitory activity of dried ginger extract might explain its use in dementia. J Pharm Pharmacol 60(10): 1375-1383.

GU X, LI K, LAYBUTT DR, HE ML, ZHAO HL, CHAN JC, XU G (2010) Bip overexpression but not CHOP inhibition attenuates fatty-acid-induced endoplasmic reticulum stress, apoptosis in HepG2 liver cells. Life Sci 87(23-26): 724-732.

HARDY J, SELKOE DJ (2002) The amyloid hypothesis of Alzheimer's disease: progress, problems on the road to therapeutics. Science 297(5580): 353-356.

HSIEH MT, WU CR, CHEN CF (1997) Gastrodin, p-hydroxybenzyl alcohol facilitate memory consolidation, retrieval but not acquisition on the passive avoidance task in rats. J Ethnopharmacol 56(1): 45-54.

KARIE N. DAHLGREN, ARLENE M. MANELLI, W. BLAINE STINE, JR., LORINDA K. BAKER,GRANT A. KRAFFT, MARY JO LADU (2002) Oligomeric and fibrillar species of amyloid- $\beta$ peptides differentially affect neuronal viability J Biol Chem 277(35): 32046-32053.

KELLER C, KADIR A, FORSBERG A, PORRAS O, NORDBERG A (2011) Long-term effects of galantamine treatment on brain functional activities as measured by PET in Alzheimer's disease patients J Alzheimers Dis 24(1): 109-123

KIM ST, KIM JD, LYU YS, LEE MY, KANG HW (2006) Neuroprotective effect of some plant extracts in cultured CT105-induced PC12 cells. Biol Pharm Bull 29(10): 2021-4.

KIM I, XU W, REED JC (2008) Cell death, endoplasmic reticulum stress: disease relevance, therapeutic opportunities. Nat Rev Drug Discov 7(12): 1013-1030.

KOGEL D, SCHOMBURG R, SCHURMANN T, REIMERTZ C, KONIG HG, POPPE M, ECKERT A, MULLER WE, PREHN JH (2003) The amyloid precursor protein protects PC12 cells against endoplasmic reticulum stress-induced apoptosis. J Neurochem 87(1): 248-256.

LIU H, BOWES RC 3RD, VAN DE, WATER B, SILLENCE C, NAGELKERKE JF, STEVENS JL (1997) Endoplasmic reticulum chaperones GRP78, calreticulin prevent oxidative stress $\mathrm{Ca}^{2+}$ disturbances, cell death in renal epithelial cells. J Biol Chem 272(35): 21751-21759.

PARK SJ, NAM KW, LEE HJ, CHO EY, KOO U, MAR W (2009) Neuroprotective effects of an alkaloid-free ethyl acetate extract from the root of Sophora flavescens Ait against focal cerebral ischemia in rats. Phytomedicine 16(11): 1042-1051.
RYU JK, CHO T, CHOI HB, WANG YT, MCLARNON JG (2009) Microglial VEGF receptor response is an integral chemotactic component in Alzheimer's disease pathology. J Neurosci 29(1): 3-13.

SIMAN R, REAUME AG, SAVAGE MJ, TRUSKO S, LIN YJ, SCOTT RW, FLOOD DG (2000) Presenilin-1 P264L knock-in mutation: differential effects on Abeta production amyloid deposition, neuronal vulnerability. J Neurosci 20: 8717-8726.

WANG M, YE R, BARRON E, BAUMEISTER P, MAO C, LUO S FU Y LUO B DUBEAU L HINTON DR, LEE AS (2010) Essential role of the unfolded protein response regulator $\mathrm{GRP} 78 / \mathrm{BiP}$ in protection from neuronal apoptosis. Cell Death Differ 17(3): 488-498.

WILEY JC, MEABON JS, FRANKOWSKI H, SMITH EA, SCHECTERSON LC, BOTHWELL M, LADIGES WC (2010) Phenylbutyric acid rescues endoplasmic reticulum stress-induced suppression of APP proteolysis, prevents apoptosis in neuronal cells. PLoS One 5(2): e9135.

WU CR, HSIEH MT, HUANG SC, PENG WH, CHANG YS, CHEN CF (1996) Effects of Gastrodia elata, its active constituents on scopolamineinduced amnesia in rats. Planta Med 62(4): 317-21.

WU PF, ZHANG Z, WANG F, CHEN JG (2010) Natural compounds from traditional medicinal herbs in the treatment of cerebral ischemia/ reperfusion injury. Acta Pharmacol Sin 31(12): 1523-1531.

WU CR, HSIEH MT, LIAO J (1996) p-Hydroxybenzyl alcohol attenuates learning deficits in the inhibitory avoidance task: involvement of serotonergic, dopaminergic systems. Chin J Physiol 39(4): 265-273.

XU X, LU Y, BIE X (2007) Protective effects of gastrodin on hypoxia-induced toxicity inprimary cultures of rat cortical neurons. Planta Med 73(7): 650-4.

YU HH, WU FL, LIN SE, SHEN LJ (2008) Recombinant arginine deiminase reduces inducible nitric oxide synthase iNOS-mediated neurotoxicity in a coculture of neurons, microglia. J Neurosci Res 86(13): 2963-2972.

YU SJ, KIM JR, LEE CK, HAN JE, LEE JH, KIM HS, HONG JH, KANG SG (2005) Gastrodia elata blume, an active component p-hydroxybenzyl alcohol reduce focal ischemic brain injury through antioxidant related gene expressions. Biol Pharm Bull 28(6):1016-1020.

YU Z, LUO H, FU W, MATTSON MP (1999) The endoplasmic reticulum stress-responsive protein GRP78 protects neurons against excitotoxicity, apoptosis: suppression of oxidative stress, stabilization of calcium homeostasis. Exp Neurol 155(2): 302-14.

XIAO-HONG Y, LI L, YAN-XIA P, HONG L, WEI-FANG R, YAN L, ANJING R, CHAO-SHU T, WEN-JUN Y (2006) Salusins protect neonatal rat cardiomyocytes from serum deprivation-induced cell death through upregulation of GRP78. J Cardiovasc Pharmacol 48(2):41-6.

XU C, BAILLY-MAITRE B, REED JC ZENG X, ZHANG Y, ZHANG S, ZHENG X A (2007) Microdialysis study of effects of gastrodin on neurochemical changes in the ischemic/reperfused rat cerebral hippocampus. Biol Pharm Bull 30(4): 801-4.

ZHANG HY, ZHENG CY, YAN H, WANG ZF, TANG LL, GAO X, TANG XC (2008) Potential therapeutic targets of huperzine A for Alzheimer's disease, vascular dementia. Chem Biol Interact 175(1-3): 396-402. 